\title{
First PGAA and NAA Experimental Results from a Compact High Intensity D-D Neutron Generator*
}

\author{
J. Reijonen, K.-N. Leung, R.B. Firestone, J. A. English, D. L. Perry, A. Smith, F. Gicquel, \\ M. Sun \\ Lawrence Berkeley National Laboratory, Berkeley, CA, 94720 USA \\ B. Bandong and G. Garabedian \\ Lawrence Livermore National Laboratory, Livermore, CA, 94551 USA \\ Zs. Revay, L. Szentmiklosi and G. Molnar \\ Institute of Isotope and Surface Chemistry, Budapest, Hungary
}

Various types of neutron generator systems have been designed and tested at the Plasma and Ion Source Technology Group at Lawrence Berkeley National Laboratory. These generators are based on a D-D fusion reaction. These high power D-D neutron generators can provide neutron fluxes in excess of the current state of the art D-T neutron generators, without the use of pre-loaded targets or radioactive tritium gas. Safe and reliable long-life operations are the typical features of these D-D generators.

All of the neutron generators developed in the Plasma and Ion Source Technology Group are utilizing powerful RF-induction discharge to generate the deuterium plasma. One of the advantages of using the RF-induction discharge is it's ability to generate high fraction of atomic ions from molecular gases, and the ability to generate high plasma densities for high extractable ion current from relatively small discharge volume.

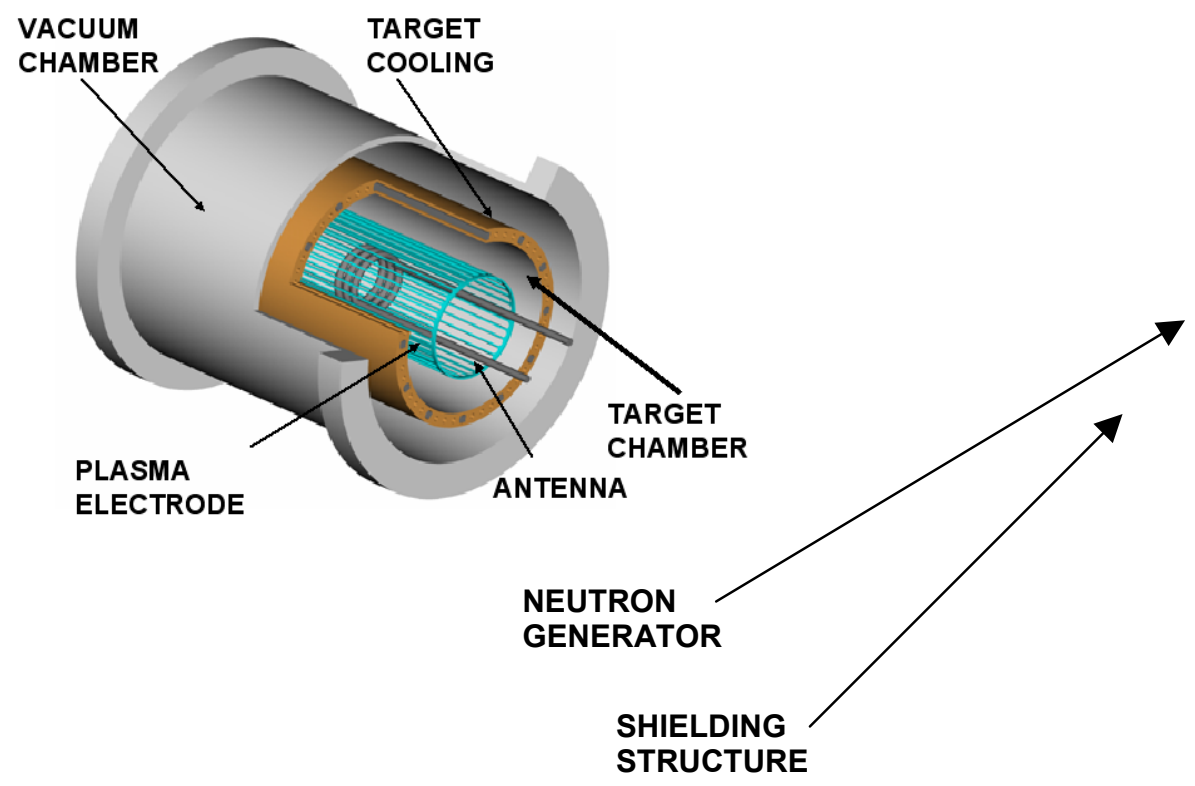

Figure 1. Schematic drawing of the co-axial neutron generator on the left, the co-axial neutron generator on the right.

\footnotetext{
* This work was supported by the U. S. Department of Energy under Contract No. DE-AC03-76SF00098
} 
The neutron generator is based on a novel co-axial design, which maximizes the target area in compact outer dimensions of the generator. A large target area enables one to operate at high beam power, thus yielding high neutron fluxes. The generator is currently operating at $120 \mathrm{kV}$ of acceleration voltage and $50 \mathrm{~mA}$ of deuterium beam current. This beam power yields a D-D neutron flux of $>10^{9} \mathrm{n} / \mathrm{s}$. This neutron generator coupled with shielding/moderator structure in a test stand at the Plasma and Ion Source Technology Group, has made possible a small-scale neutron facility for NAA (Neutron Activation Analysis) and PGAA (Prompt Gamma Activation Analysis) experiments. Figure 1 shows a schematic of the co-axial neutron generator and its placement in the shielding/moderator structure. The size of the shielding is approximately $1.2 \times 1.2 \times 1.2 \mathrm{~m}$. Figure 2 shows the drawing of the neutron facility together with shielding structure and the control rack.

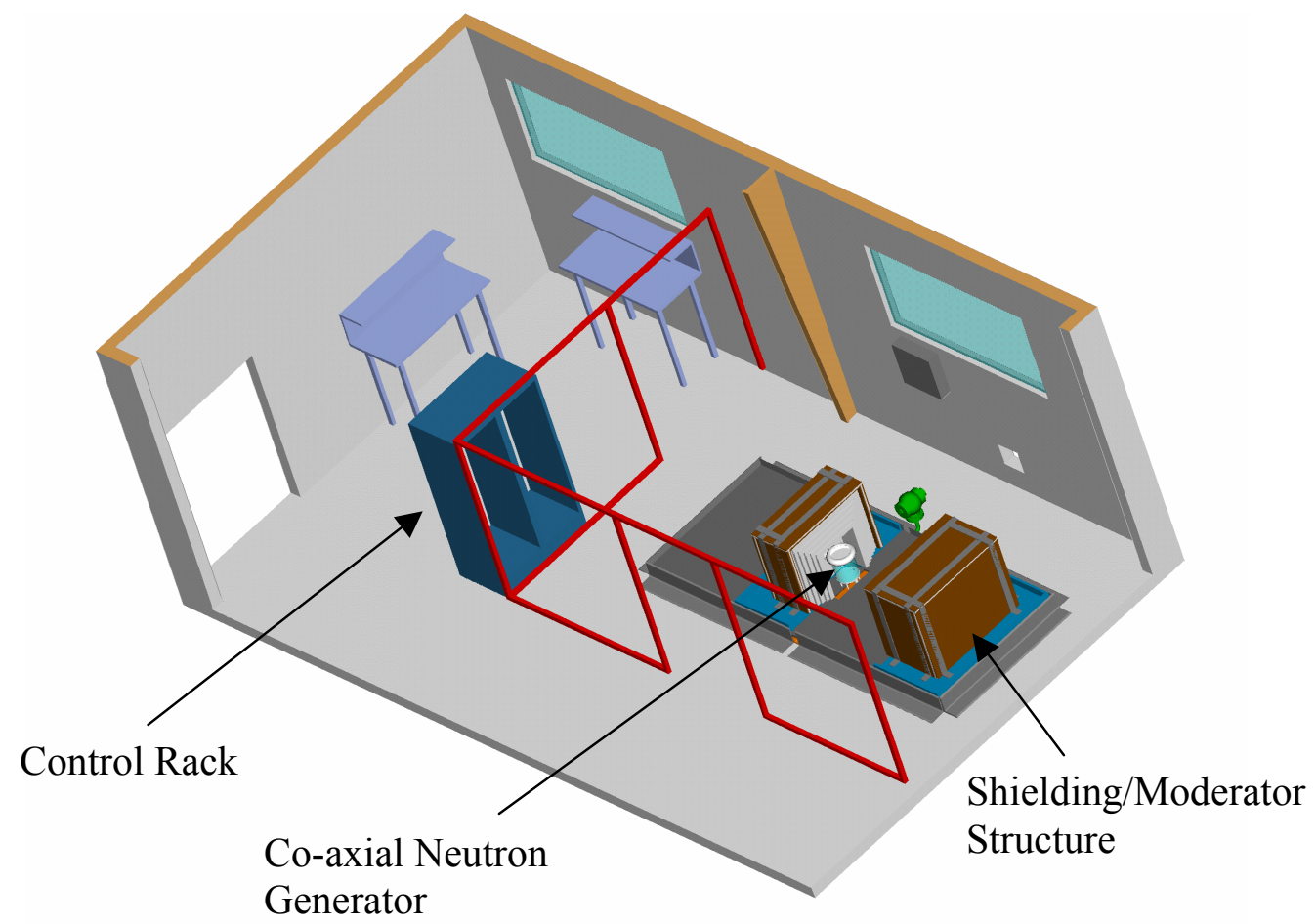

Figure 2 Layout of the neutron facility.

Figure 3 shows a comparison of the experimental neutron fluency with MCNP calculations. The fluency was measured at various depths in the polyethylene moderator by activating thin copper disks and counting the ${ }^{66} \mathrm{Cu}(\mathrm{t} 1 / 2=5.1 \mathrm{~m}) 1039-\mathrm{keV}$ gamma-ray activity. These measurements were performed axially to the left center of the generator beginning $\approx 25 \mathrm{~cm}$ from the titanium target. The MCNP calculation was normalized to the neutron fluency measurements after correction for a significant epithermal contribution. These results correspond to a generator output of $\approx 10^{9} \mathrm{n} / \mathrm{s}$, from the MCNP calculation, and are consistent with separate $\mathrm{Pu} / \mathrm{B}$ standard calibrations. A large epithermal flux was observed and accounted for in figure 3. 


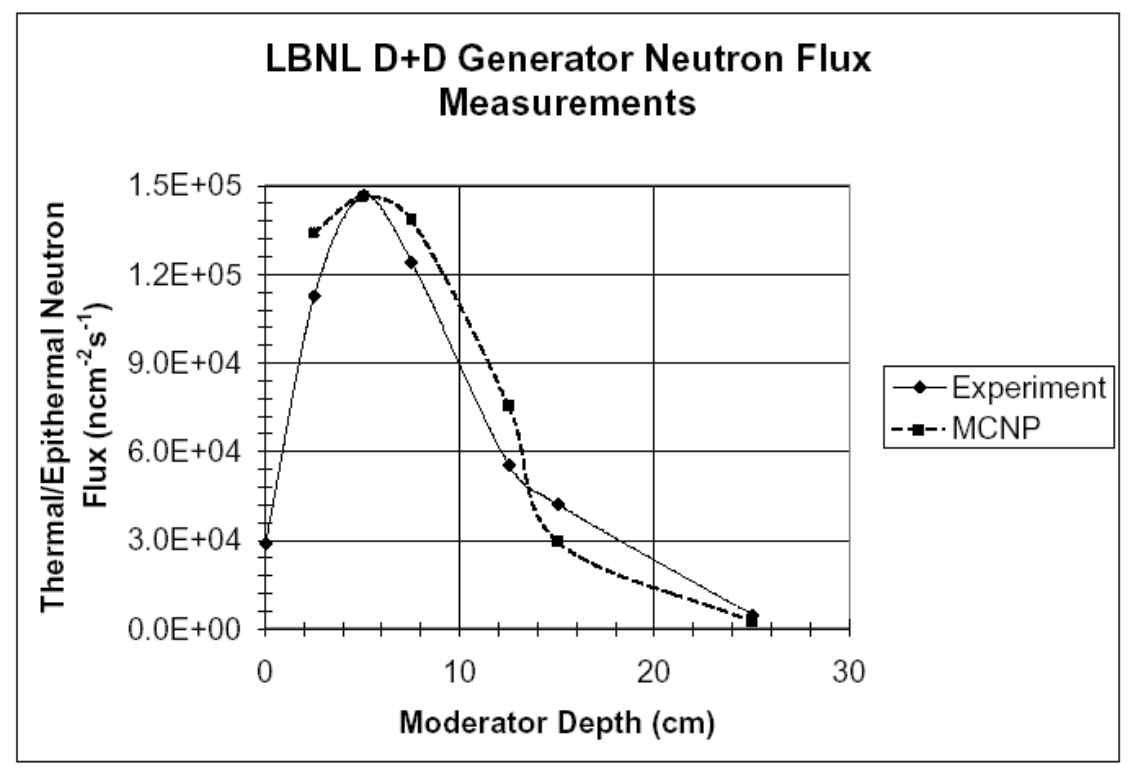

Figure 3. Neutron flux at various depths into the moderator

NAA can be applied at the LBNL neutron facility to analyze $\approx 50$ elements. Figure 4 shows an NAA spectrum for the analysis of $\mathrm{NaCl}$ measured using the neutron generator operating at a flux of $\approx 10^{9}$ $\mathrm{n} / \mathrm{s}$ corresponding to a fluency of $\approx 10^{5} \mathrm{ncm}^{-2} \mathrm{~s}^{-1}$ at the target position.

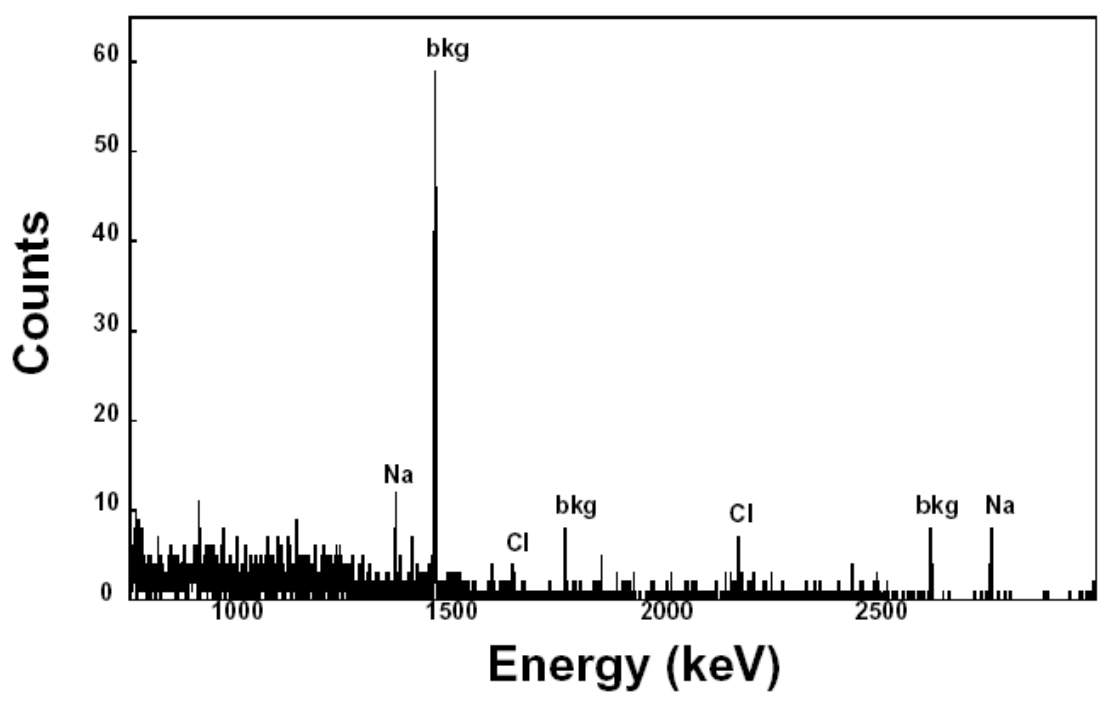

Figure 4. NAA spectrum of $\mathrm{NaCl}$. The sample was irradiated for 15 minutes and counted for 10 minutes with an unshielded 20\% HPGe detector. 
PGAA, a nondestructive method capable of the simultaneous analysis of $<1 \mathrm{mg}$ of all elements except helium, has been demonstrated with $10^{6} \mathrm{ncm}^{-2} \mathrm{~s}^{-1}$ guided neutron beams at nuclear reactors. Modest improvements in the LBNL neutron generator output and moderator design should allow us to achieve similar sensitivities. Figure 5 shows the prompt gamma-ray spectrum of the neutron generator, moderator, and support materials where the elements $\mathrm{H}, \mathrm{B}, \mathrm{C}, \mathrm{O}, \mathrm{Al}, \mathrm{Si}, \mathrm{Cl}, \mathrm{Fe}$, and $\mathrm{Ti}$ are identified.

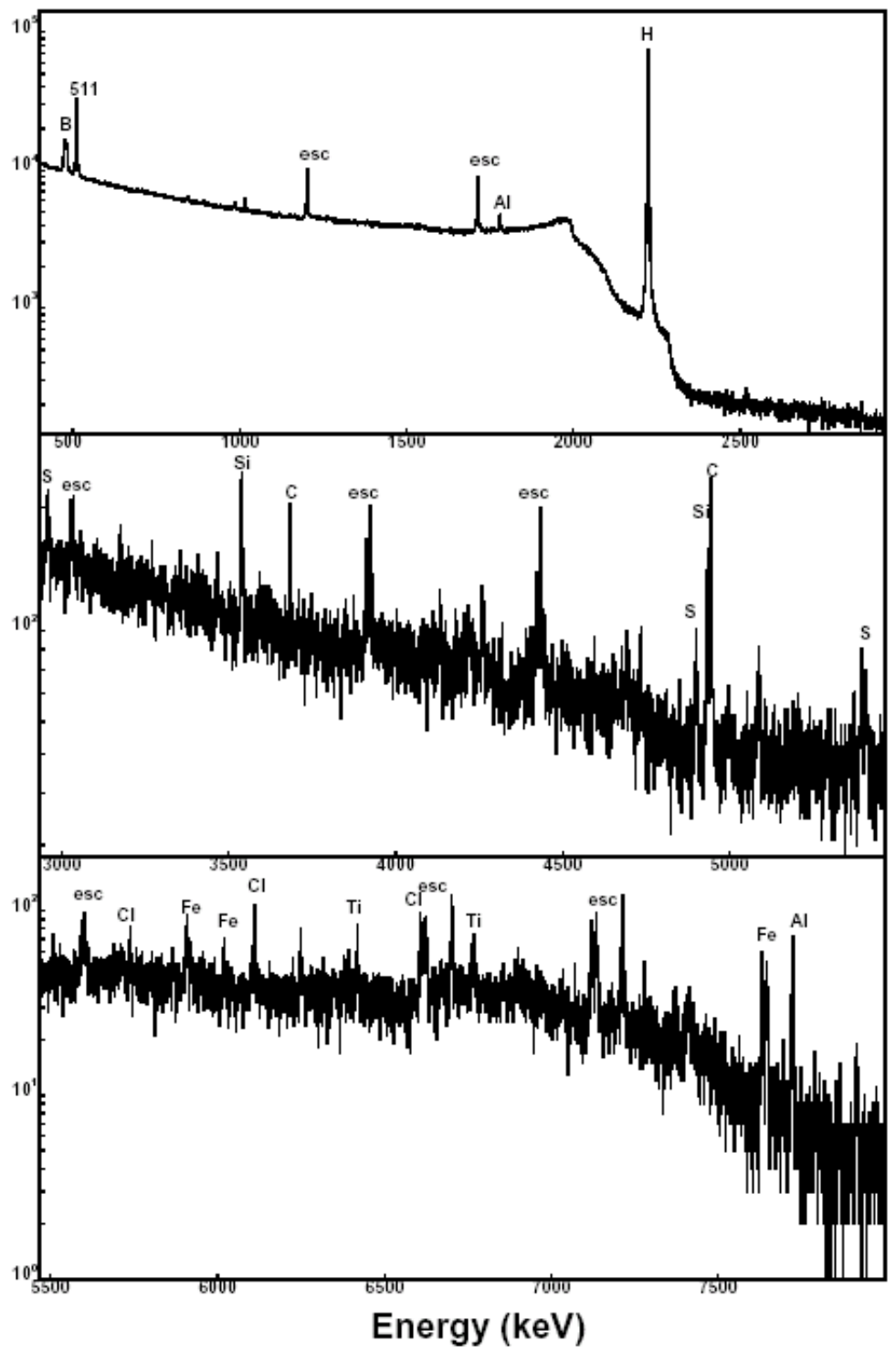

Figure 5. Prompt gamma-ray spectrum of moderator, shielding, and neutron generator materials. The $20 \%$ HPGe spectrometer was shielded with borated silicone rubber to limit neutron damage and placed outside of the shielding $\approx 50 \mathrm{~cm}$ from the neutron generator.

These measurements have demonstrated that a simple and compact D-D neutron generator can be used for PGAA and NAA applications. Currently these measurements have to be performed in a fission reactor or by using intense radioisotopes. Work is in progress to improve the neutron output and diagnostics set-up so that one can use these techniques for applications such as legacy material identification. Results of these studies will be presented in the near future. 